\title{
Air Pollution and Death Due to Cardiovascular Diseases (Case Study: Isfahan Province of Iran)
}

\author{
Masoumeh Rashidi, Mohammad Hossein Rameshat and Hadi Gharib
}

Additional information is available at the end of the chapter

http://dx.doi.org/10.5772/50416

\section{Introduction}

Complex interaction between anthropogenic activities, air quality and human health in urban areas, sustains the need for the development of an interdisciplinary and integrated risk-assessment methodology. Such study would help for the establishment of a sustainable development in urban areas that can maintain the integrity of air quality and preserve human health. For the last century, the worldwide development of anthropogenic activities as well as modifications of spatial management and occupational uses in urban areas have lead to considerable degradation of air quality through the production of a large number of pollutants(1). Sustainable development introduced during the 1980 represents a sure mean to withstand deleterious effects of pollutants observed in most large cities. However, making effective such concept in urban areas requires the validation of a risk-assessment methodology that can integrate and connect anthropogenic uses of urban areas, air pollution and the occurrence of some pathologies. One actual and major challenge is how to apprehend complexity of systems due to the interaction of multiple parameters at each level of organization (anthropogenic or biological, individual or population) and scale (regional or local). Such challenge can be facilitated by the development of a multidisciplinary and integrative approach using tools from biology and geography that can allow the analysis of complex systems For example, the introduction of biomarkers at the cellular and molecular levels in the detection of early biological events induced by pollutants constitutes promising tools in estimating exposure of human population. Cardiovascular disease is one of the most prevalent diseases in the world and it is expected to be the main cause of death by 2020(2). Nowadays, the cardiovascular diseases are one of the important issues in health care. The prevalence of this disease in more countries has been rising as the third leading cause of death and the first group of chronic diseases and concerns the health and treatment in the Iran. New eating habits, increased smoking, increasing air population, and the older demographic composition are the predisposing factors in increasing the cases of 
cardiovascular diseases. It is estimated that one third of cases of cardiovascular disease is preventable and a third contingent on early diagnosis, are potentially treatable. Scientific advances and progress in many cases of cardiovascular diseases have been caused to disease containment and control of its causes and have provided the increase long-term survival for patients with a wide range of types of invasive diseases(3). Despite the lack of attention to air pollution, one of the main reasons is the occurrence of cardiovascular diseases (4). For example, nearly one million ton of Plumb is added to the globe soils annually in which large quantities of atmospheric dust, scattering ash, and chemical fertilizers used in agriculture, industry and urban wastes are included. In many cases, air pollution factors affecting disease is less under consideration (5). Isfahan province, with an area of about 107,045 square kilometers, equivalent to $6.3 \%$ of the total area of Iran is located between 30 degrees 43 minutes and 34 degrees 27 minutes north latitude and 49 degrees 38 minutes and 55 degrees 32 minutes east of the Greenwich meridian(6,7). The province is 1550 meters above the sea level altitude (Figure1). This study aimed at mapping the distribution of death due to Cardiovascular Diseases and its relationship with Air Pollution in this province.

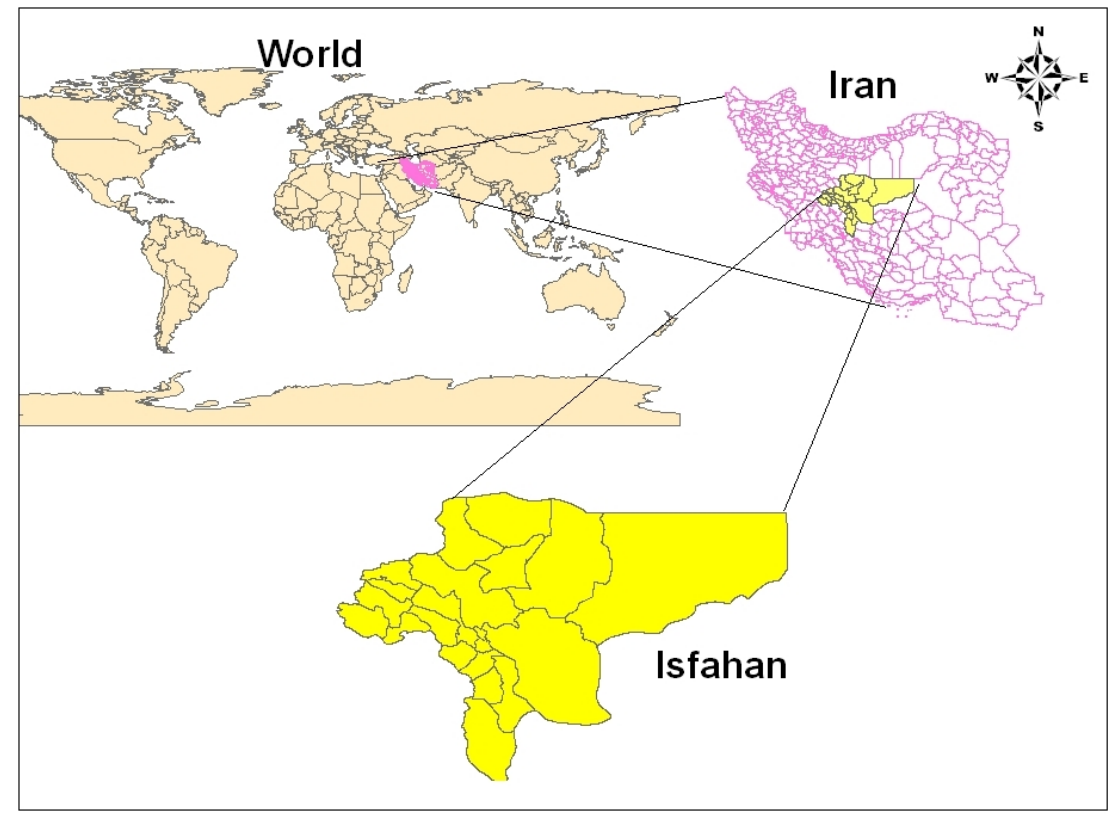

Figure 1. Geographical situation of Isfahan province

\section{Method used}

The software of geographic information system (GIS) was used after entering data in the mapping information table; spatial distribution was mapped and distribution of Geographical Epidemiology of Death Due to Cardiovascular Diseases in the was determined this case study, the rate of all the deaths in Isfahan province (Iran) within 2005 to 2009 was 
provided. The collected data was used to find out the rate of deaths due to cardiovascular diseases and preparing geographical distribution maps. Then, by putting down the death rates for different sexes (men and women), the geographical distribution map for deaths with regards to cardiovascular diseases was drawn.

\section{Air pollution}

Any visible or invisible particle or gas found in the air that is not part of the original, normal composition. Generally any substance that people introduce into the atmosphere that has damaging effects on living things and the environment is considered air pollution. Carbon dioxide, a greenhouse gas, is the main pollutant that is warming Earth. Though living things emit carbon dioxide when they breathe, carbon dioxide is widely considered to be a pollutant when associated with cars, planes, power plants, and other human activities that involve the burning of fossil fuels such as gasoline and natural gas. In the past 150 years, such activities have pumped enough carbon dioxide into the atmosphere to raise its levels higher than they have been for hundreds of thousands of years. Other greenhouse gases include methane-which comes from such sources as swamps and gas emitted by livestock - and chlorofluorocarbons (CFCs), which were used in refrigerants and aerosol propellants until they were banned because of their deteriorating effect on Earth's ozone layer. Another pollutant associated with climate change is sulfur dioxide, a component of smog (9). Sulfur dioxide and closely related chemicals are known primarily as a cause of acid rain. But they also reflect light when released in the atmosphere, which keeps sunlight out and causes Earth to cool. Volcanic eruptions can spew massive amounts of sulfur dioxide into the atmosphere, sometimes causing cooling that lasts for years. In fact, volcanoes used to be the main source of atmospheric sulfur dioxide; today people are(10). Industrialized countries have worked to reduce levels of sulfur dioxide, smog, and smoke in order to improve people's health. But a result, not predicted until recently, is that the lower sulfur dioxide levels may actually make global warming worse. Just as sulfur dioxide from volcanoes can cool the planet by blocking sunlight, cutting the amount of the compound in the atmosphere lets more sunlight through, warming the Earth. This effect is exaggerated when elevated levels of other greenhouse gases in the atmosphere trap the additional heat.

\subsection{Major classes of air pollution}

- $\quad$ Carbon Oxides (CO and CO2)

- Sulfur Oxides (SO2)

- Nitrogen Oxides (NO and NO2)

- Volatile Organic Compounds (VOCs - CFCs)

- Suspended Particulate Matter (soot, dust, asbestos, lead etc).

- Photochemical Oxidants (ozone O3)

- Radioactive Substances (Radon)

- Hazardous Air Pollutants (carcinogens, etc) (11). 


\subsection{Where do these pollutants come from?}

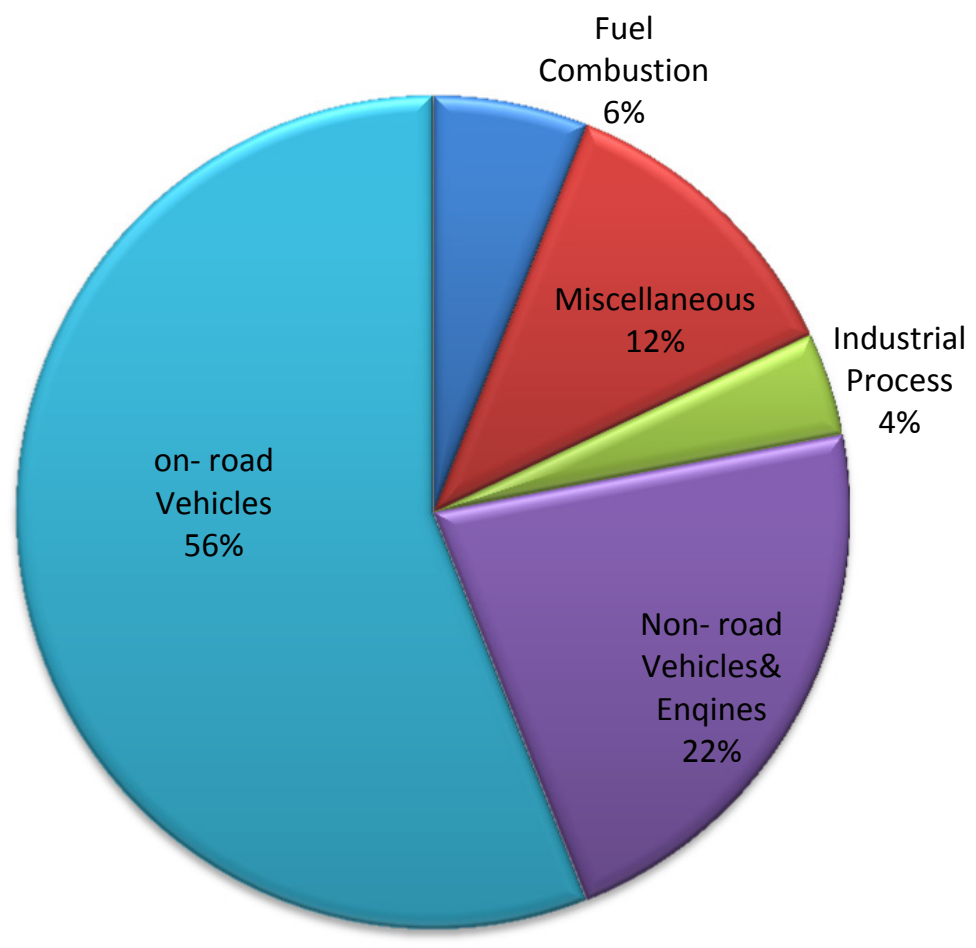

Figure 2. Source of Air Pollution (12)

\begin{tabular}{|l|l|}
\hline \multicolumn{1}{|c|}{ Health and Effects of Air Pollution } \\
\hline Ozone (O3) & $\begin{array}{l}\text { Health Effects } \\
\text { Decreases lung function and causes respiratory symptoms, such as coughing } \\
\text { and shortness of breath; aggravates asthma and other lung diseases leading to } \\
\text { increased medication use, hospital admissions, emergency department (ED) } \\
\text { visits, and premature mortality. }\end{array}$ \\
\hline $\begin{array}{l}\text { Particulate } \\
\text { Matter (PM) }\end{array}$ & $\begin{array}{l}\text { Short-term exposures can aggravate heart or lung diseases leading to } \\
\text { symptoms, increased medication use, hospital admissions, ED visits, and } \\
\text { premature mortality; long-term exposures can lead to the development of } \\
\text { heart or lung disease and premature mortality. }\end{array}$ \\
\hline Lead (Pb) & $\begin{array}{l}\text { Damages the developing nervous system, resulting in IQ loss and impacts on } \\
\text { learning, memory, and behavior in children. Cardiovascular and renal effects } \\
\text { in adults and early effects related to anemia. }\end{array}$ \\
\hline
\end{tabular}




\begin{tabular}{|l|l|}
\hline $\begin{array}{l}\text { Oxides of } \\
\text { Sulfur (SOx) }\end{array}$ & $\begin{array}{l}\text { Aggravate asthma, leading to wheezing, chest tightness and shortness of } \\
\text { breath, increased medication use, hospital admissions, and ED visits; very } \\
\text { high levels can cause respiratory symptoms in people without lung disease. }\end{array}$ \\
\hline $\begin{array}{l}\text { Oxides of } \\
\text { Nitrogen } \\
\text { (NOx) }\end{array}$ & $\begin{array}{l}\text { Aggravate lung diseases leading to respiratory symptoms, hospital } \\
\text { admissions, and ED visits; increase susceptibility to respiratory infection. }\end{array}$ \\
\hline $\begin{array}{l}\text { Carbon } \\
\text { Monoxide } \\
\text { (CO) }\end{array}$ & $\begin{array}{l}\text { Reduces the amount of oxygen reaching the body's organs and tissues; } \\
\text { aggravates heart disease, resulting in chest pain and other symptoms leading } \\
\text { to hospital admissions and ED visits. }\end{array}$ \\
\hline $\begin{array}{l}\text { Ammonia } \\
\text { (NH3) }\end{array}$ & \begin{tabular}{l} 
Contributes to particle formation with associated health effects. \\
\hline $\begin{array}{l}\text { Volatile } \\
\text { Organic } \\
\text { Compounds } \\
\text { (VOCs) }\end{array}$
\end{tabular} \\
\hline $\begin{array}{l}\text { Mercury } \\
\text { (Hg) }\end{array}$ & $\begin{array}{l}\text { Some are toxic air pollutants that cause cancer and other serious health } \\
\text { problems. Contribute to ozone formation with associated health effects. }\end{array}$ \\
\hline $\begin{array}{l}\text { Other Toxic } \\
\text { Air } \\
\text { Pollutants }\end{array}$ & $\begin{array}{l}\text { Cause cancer; immune system damage; and neurological, reproductive, } \\
\text { developmental, respiratory, and other health problems. Some toxic air } \\
\text { pollutants contribute to ozone and particle pollution with associated health } \\
\text { effects. }\end{array}$ \\
\hline
\end{tabular}

Table 1. Effects of air pollution on human health (13)

\section{Cardiovascular disease and air pollution}

Diseases of the heart or blood vessels, or cardiovascular disease, and in particular coronary heart disease (harm to the heart resulting from an insufficient supply of oxygenated blood) are leading causes of death in the Iran (14). Prevention of these killers has traditionally focused on controlling hypertension, cholesterol levels, and smoking and making healthy choices in regard to diet, exercise, and avoiding second-hand smoke. However, accumulating evidence indicates that air pollutants contribute to serious, even fatal damage to the cardiovascular system - and air pollution is a factor that you can't control just through healthy lifestyle. Harmful air pollutants lead to cardiovascular diseases such as artery blockages leading to heart attacks (arterial occlusion) and death of heart tissue due to oxygen deprivation, leading to permanent heart damage (infarct formation). The mechanisms by which air pollution causes cardiovascular disease are thought to be the same as those responsible for respiratory disease: pulmonary inflammation and oxidative stress.

\section{Finding in case study}

The population includes 35273 records from death due to Cardiovascular Diseases in the province. The period studied, according to the number of samples is sufficiently reliable and, over 5 years (from 2005 until early 2009) was considered .Impaired synthesis of hemoglobin 
and anemia, Cardiovascular Diseases, Respiratory Diseases, malignant disease, hypertension, kidney damage, miscarriages and premature infants, nervous system disorders, brain damage, male infertility, loss of learning and behavioral disorders in children are from the negative effects of high concentrations of the Air Pollution in the body. Air Pollution exists naturally in the environment, but in most cases the increase in quantity, is the result of human activities. There were 19614 men (i.e. 56\%) and 15659 women (44\%) regarding the mentioned mortality rate, showing more men than women. Analysis of the mortality conforming rate of cardiovascular diseases in men shower to be highest in Isfahan, Najafabad, Borkhar\&Meimeh, Fereidan, Natanz, Ardestan, Mobarakeh, Lenjan\&Naein, respectively and the lowest rates were in Golpayegan, Tiran \&Karvand, Falavarjan\&Chadegan, that means that mortality rates were higher in central counties of the province.This is observed for the total population, and men and women separately. It was significant in most of the central counties of the province.

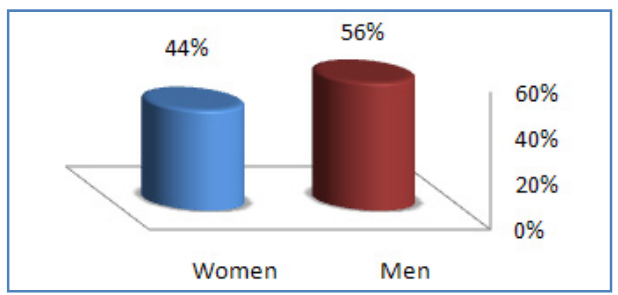

Figure 3. Graph of statistical comparison death due to cardiovascular diseases in Men\& Women

After drafting the diagram for distribution of death due to cardiovascular diseases in Men\& Women (Figure 3). Death rate was higher in men than women.

\section{Cities with higher air pollution}

Cities such as Isfahan, Najafabadf, Borkhar\&Meimeh, Ardestan and Natanz,... are Population centers and air pollution in these cities, according to survey is more than the other cities because human activity is higher in these cities, The following map shows the cities with high pollution in Isfahan province(Figure4).

Air pollution levels in the study province are increased and with increased air pollution also death due to cardiovascular disease has gone up (Figure5, 6).

Most of the mortality rates with regards to cardiovascular diseases in women was in Isfahan, Najafabadf, Borkhar\&Meimeh, Ardestan and Natanz that is much less in comparison to men (Figure7, 8). This means that men have gone ahead of women in this respect. The role of weather pollution in emergence of cardiovascular diseases in urban communities is considered as an effective factor that could not be modified, such that comforting environmental pollution has been considered relative to different cardiovascular effects including angina, heart stroke and hearty failures. Heart disease is the bitter achievement of advance technology. The useful role of technology somewhat allows people to have longer life and the harmful role of technology provides the change in life style and immobility. 
Air Pollution and Death Due to Cardiovascular Diseases (Case Study: Isfahan Province of Iran) 181

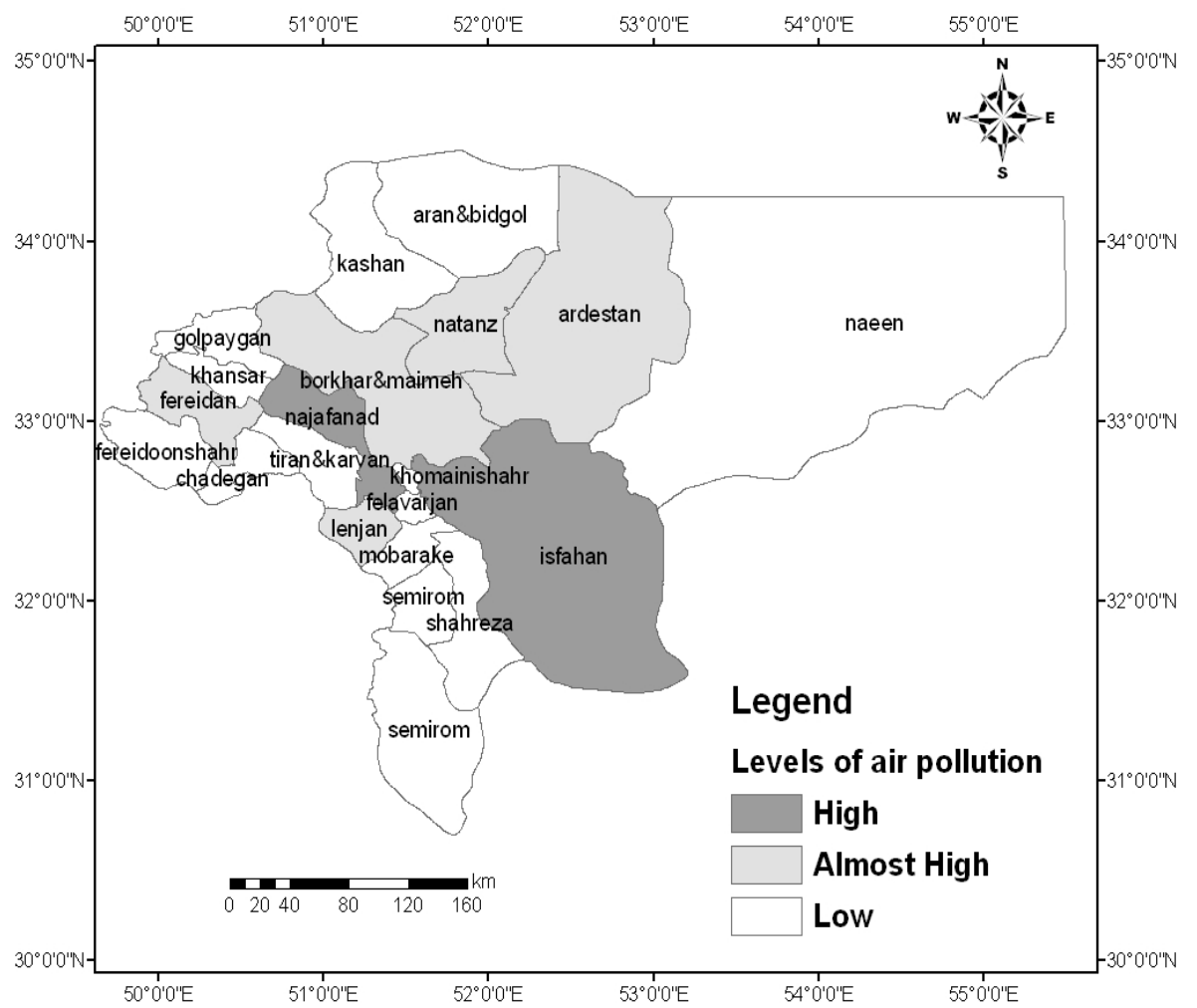

Figure 4. Levels of Air Pollution in Isfahan province

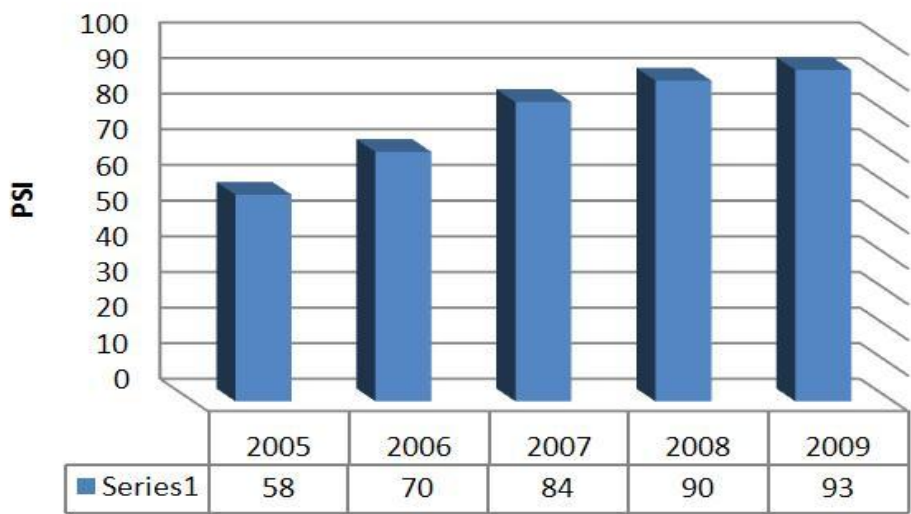

Figure 5. A comparison chart increase air pollution in the years 2005-2009 


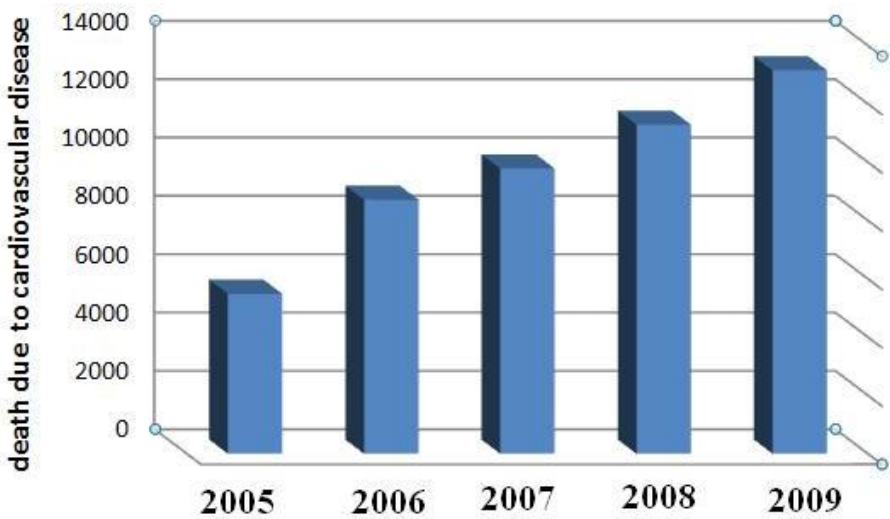

Figure 6. A comparison chart increase death due to cardiovascular disease in the years 2005-2009

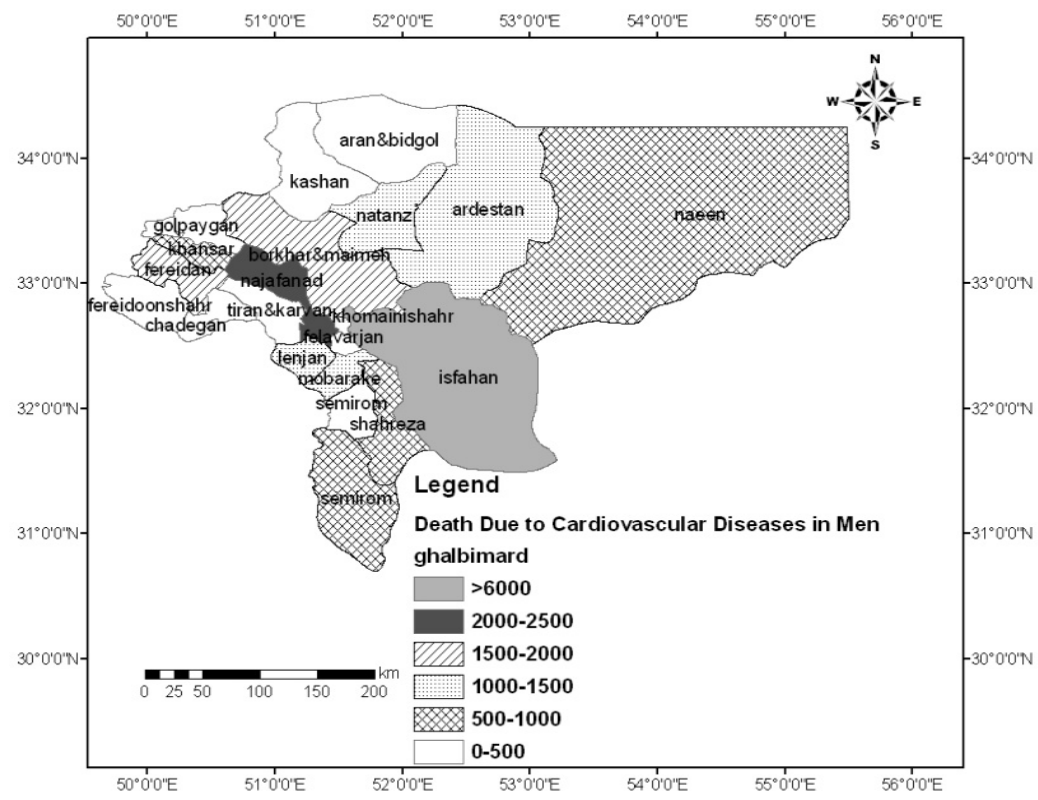

Figure 7. Spatial distribution of death due to cardiovascular diseases in Men 


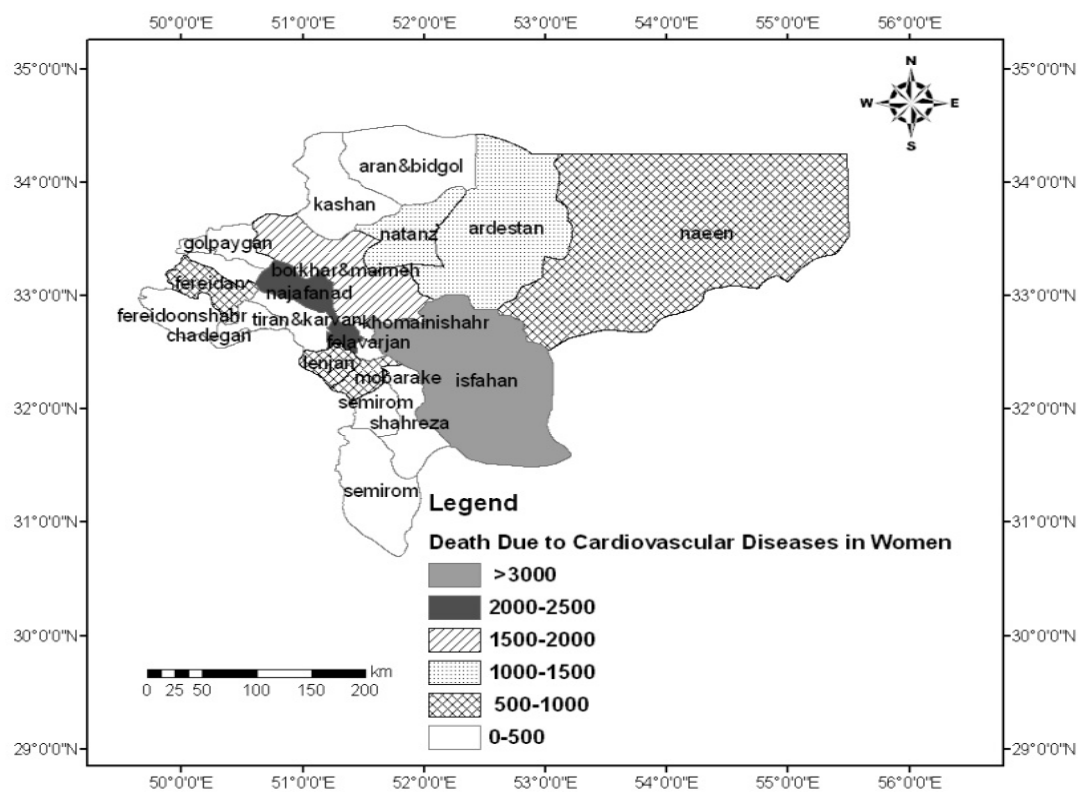

Figure 8. Spatial distribution of death due to cardiovascular diseases in Women

\section{Conclusion}

By drawing the geographical distribution of mortality due to cardiovascular reasons (by the use of GIS software), it was observed that the rate of mortality I higher in control and main counties of the province, which could be due to two reasons: 1) Due to existence Air pollution in the main cities of the province including Isfahan, Najafabad, Borkhar\&Meimeh, More vehicles are movement, in these cities than the other places in the province. 2) Improper diet including saturated fat due to mechanized life and better welfare in these regions and immobility, use of new technologies, and environmental pollutions including the existence of some specific elements \& hard urban life all express the verification of the hypothesis. Also, it was observed that mortality in men is higher in the province than women and there could be different reasons for that, which may include Most men work outside the home in , male hormones, some social factors, increasing fat around stomach in men, stimulating behaviors and sometimes offensive behavior, not observing the weight, stress in work places and smoking. Since the basis for campaign against non-epidemic diseases, including cardiovascular disease is changing the people's life style, it seems that it can be achieved by instructions and training people, making required polices and enacting laws and necessary regulations to provide on environment that is suitable for promoting healthy behaviors in life. By proper intervention in the society the effects of risk factors could be totally eliminated or reduced. Even partial changes could be very useful. Prevention is possible by intervening the risk factors in cardiovascular diseases such as identification of some elements in the environment and finding the place of their distribution, avoiding the use of air pollutants or 
using them as little as possible, proper use of technology, changing diets, behaviors, physical habits, reducing anxieties and mental stresses and other environmental diseases.

\section{Author details}

Masoumeh Rashidi

Department of Geography, and Medicine Geography Researchers, the University of Isfahan, Iran

Mohammad Hossein Rameshat

Department of Geography, Isfahan University, Iran

Hadi Gharib

Iran Space Agency, Iran

\section{References}

Azizi, F, (2001), "Epidemiology and control of common diseases in Iran", Volume II, Tehran University Press, 2001.

Braunwald E. (2005), Approach to the Patient with Cardiovascular Disease. In: Kasper DL, Branwald E, Favci AS, Havser SL, Longo DL, Jameson JL. Harrison's Principles of Internal Medicine. McGraw-Hill. New York, 1301-4.

Reddy KS, (2004), Cardiovascular Disease in Non-Western Countries Engl J Med. 350: 2438-40.

Nagavi, M. (2005), the pattern of mortality within 23 provinces of Iran in 2003, Health Deputy, Iranian Ministry of Health. Tehran.

Rezaeian M, Dunn G. St. Leger, S. Appleby L. (2007), Geographical epidemiology, spatial analysis and geographical information systems: a multidisciplinary glossary. J Epidemiol Community Health; 61: 98-102.

Rezaeian, M. Dunn, G. St. Leger, S. Appleby L. (2004), the production and interpretation of disease maps: A methodological case study. Soc Psychiatry Psychiatr Epidemiol.; 39: 947-54.

Rezaeian, M. (2004), an introduction to the practical methods for mapping the geographical morbidity and mortality rates.Tollo-e-behdasht. 2: 41-51.

Isfahan Health Center, Center for death Statistics, 2009.

Samet, J. M., Zeger, S. L., Kelsall, J., Xu, J., and Kalkstein, L. (1997), "Air Pollution, Weathera nd Mortalityi $n$ Philadelphia," in ParticulateA ir Pollution and Daily Mortality: Analyses of the Effects of Weather and Multiple Air Pollutants, The Phase IB report of the Particle Epidemiology Evaluation Project, Cambridge, MA: Health Effects Institute.

Schwartz, J. (1994), "Air Pollution and Daily Mortality: A Review and Meta Analysis," EnvironmentaRl esearch, 64, 36-52.

Zeger, S. L., Dominici, F., and Samet, J. M. (1999), "Harvesting-Resistant Estimates of Pollution Effects on Mortality,"E pidemiology, 8 9, 171-175.

Research Centre for Atmospheric Chemistry, Ozone and Air Pollution in Isfahan province.

WHO (2007). Health risks of heavy metals from long-range transboundary air pollution. Copenhagen, World Health Organization Regional Office for Europe.

Rashidi M, Ramehsat M.H, Ghias, M(2011), Geographical Epidemiology of Death Due to Cardiovascular Diseases in Isfahan Povince, Iran; Journal of Isfahan Medical School, Vol 29, No 125, 1st week, April. 